\title{
Forming the association-like organisation: on civil society, welfare provision and sport as a means of social inclusion
}

\section{David Ekholm ${ }^{1}$ (D) Magnus Dahlstedt ${ }^{2}$}

Received: 4 June 2018 / Accepted: 28 August 2018 / Published online: 14 September 2018

(C) The Author(s) 2018

\begin{abstract}
This article concern how sport is conceptualised as a response to challenges of segregation, exclusion and conflict. We examine a sports-based social intervention and analyse how an association-like organisation is set up as a means of promoting social inclusion and community. The examinations are based on statements made by representatives of the intervention and analysed from a governmentality perspective. In discourse, it is articulated that self-generating social exclusion reinforces patterns of ethno-cultural segregation. In response, the sports-based intervention provides an association-like arena, where rolemodels can reach out to youths, enact proper conduct and Swedish-ness, introduce to Swedish civil society associations and promote social inclusion. The association-like organisation alerts how traditional sector divides are contingent, and that the welfare state and civil society are entangled. Consequently, we need to look beyond this divide in order to focus on how social problems are countered in contemporary society.
\end{abstract}

Keywords Governing $\cdot$ Welfare $\cdot$ Social exclusion $\cdot$ Social problems $\cdot$ Community

\section{Introduction}

In the mainstream of contemporary political debate are social problems emerging due to an increase in segregation. Social marginalisation, inequality and exclusion are some of the concepts used to describe the tensions and conflicts arising, potentially undermining social solidarity and community (Schierup et al. 2014; Stigendal 2016).

David Ekholm

david.ekholm@liu.se

Magnus Dahlstedt

magnus.dahlstedt@liu.se

1 Department for Studies of Social Change and Culture, Linköping University, Norrköping, Sweden

2 Department of Social and Welfare Studies, Linköping University, Norrköping, Sweden 
Here, the role of the welfare state and society in general for acting against conflict and social problems are highlighted. In relation, welfare provision has been focusing not least on locally based social pedagogic interventions in suburban areas of exclusion (Dahlstedt and Ekholm 2018). Here, the roles of the welfare state and of civil society as well as the relations between them as divided sectors are spotlighted (Herz 2016; Villadsen 2008) with respect to countering conflict and tension and for promoting community, social cohesion and solidarity (Ekholm and Dahlstedt 2017).

One specific example of such public-private partnerships or collaborations between public agencies and civil society, concerns how sport practices are construed as arenas for acting out social inclusion interventions (Collins and Haudenhuyse 2015), not least in Sweden (Ekholm 2016). A key feature, here, concerns transformations of the relationships between state and civil society, which at a first look may be understood in terms of increasing instrumentalization of sport and civil society organisations (Fahlén and Stenling 2015; Norberg 2011). Particularly, there has been an increase in government grants specifically designated with respect to social inclusion and integration of migrants (Government Offices 2015). Utilising sport as a means of social policy objectives is a common and international contemporary trend (Collins and Haudenhuyse 2015), however, with some particular implications when it comes to integrating voluntary sport clubs and associations in forming and reaching social policy objectives (cf. Norberg 2010, 2011). Sport associations, generally seen as part of the civil society, enjoys a particular autonomy from public administrations, though implicitly granted based on the presumed benefits expected from sport participation with respect to public health and social inclusion, for instance (Norberg 2010, 2011). Sports-based interventions for social inclusion can target both inclusion in sport, where participation is seen as an end in itself, and inclusion through sport, where sport practices are utilised as a means of becoming included in society in a broader meaning (Collins and Haudenhuyse 2015). In this article, we spotlight a sports-based intervention conducted in a suburban area in a Swedish city. A question raised in relation to the sports-based intervention observed here, concern the ways in which the practices observed contribute to inclusion in sport practices or to inclusion in wider society, and the ways in which this regard inclusion in or through sport. Furthermore, questions are raised about the kind of community, cohesion and solidarity promoted and made realisable.

We focus on a sports-based social intervention, Football for Inclusion, performed in two suburban areas (the Area), which can be described as particularly socially vulnerable, in an average-sized Swedish city (the City). The practice aims for inclusion and participation in sport, but at the same time with the grander objective of providing social inclusion in society through sport participation. Gaining access to and being granted inclusion in sport are seen as a way for becoming included in society. The aim of the article is to analyse how public-private partnerships are arranged and how relations between different actors are formed in relation to provision of welfare. Specifically, we explore the formation of the kind of organisational set up, perceived to enable social inclusion in and through sport. What makes this analysis particularly important is the problematization of the rationalities of forming social inclusion, community and solidarity, regarding into what the youth are supposed to be included in as well as how such inclusion and formation of community should be achieved.

Briefly, the argument put forth in this article is that managers, coaches and cooperating partners within the intervention examined, highlight problems of urban 
segregation resulting in tensions and conflicts among youth in the local residency, supposedly threatening community and solidarity in society. In response, the sportsbased intervention ideally provides opportunities for social inclusion and for supporting community and solidarity by means of youth sport participation. We illustrate how organisational cooperation allegedly forms cross-sectoral and mutual partnership, how the association-like form of organisation is instituted, and how community-based rolemodels here become important facilitators and conductors of solidarity and social inclusion. Association-like is a recurring concept in the analysis. This is an analytical finding in the article, referring the organisational amalgamation of civil society-based sport association and public sector social inclusion intervention, promoted as a metaphor of the traditional voluntary sport club, manifesting the nostalgia of authentic Swedish community.

\subsection{Background and context}

We investigate Football for Inclusion, focusing on how the formation of public-private partnership is acted out as a response to both tensions and conflicts in general and to exclusion and segregation specifically. The approach is not theoretically driven in the first instance, but primarily empirically, grounded on the explicit objective of the program to use football as a means of responding to social problems. This, for instance, is explicated in the following excerpt.

We're on a route towards a catastrophe in Sweden... [...] You can see this in Botkyrka, Fittja and Tensta. With a completely different tendency towards violence, with a completely different criminality, with a completely different formation of gangs - which means, and I mean this in all seriousness, that people look to join gangs. And the gang is more important than surviving. You can murder people who are in opposition, who come from other gangs. This is what we think we must try to avoid. And there, the aim is to start right from the first class so that the children will not end up in these criminal gangs, but in the world of sports instead, or preferably within the social world, where people integrate with those who come from other areas. [...] We do not need to assume the worst, but we see that the City has a great deal of... a strong formation of gangs with very violent activities [excerpt A].

The quote, articulated by the Initiator of Football for Inclusion, dramatically illustrates how the challenges and problems of tensions and conflict are portrayed. The excerpt sets the stage for an intervention, aiming to prevent future problems. The situation in this particular suburb is described as chaotic and it runs the riskunless something is done about it - of deteriorating and thereby also constituting a threat to solidarity and cohesion in society as a whole. Here, the Big City specifically Stockholm - appears as an antithesis to the desirable - the cohesion, community and harmony of the smaller city.

Football for Inclusion was started in 2014 by two of the City's more prominent and established football associations, with the objective of "using organised football to improve young people's social and language skills and work towards integration in Swedish society", as well as to "get children and young people to become active during 
their leisure time" and to "stimulate friendship between young people from different cultures". The sports activities, consisting of organised football, are aimed at children in the age range 8-12 at some of the schools in the two areas. In sum about 200 children takes part in the practices. The activity is run in two of the City's most socially and economically distressed as well as ethnically segregated areas. Collaboration between different actors constitutes a central organisational element of Football for Inclusion. It is run as a public-private partnership in collaboration with schools and after-school centres. Practices are carried out during and after school-time. Teachers are not involved directly in the practices but the children are reached out to within their school classes.

The intervention is financed with the support of the municipality. The municipality, and specifically, the board of culture- and leisure, provides with financial support based on the social benefits expected from the intervention. Additionally, the District Sports Federation and the District Football Federation provides with minor grants to the associations carrying out the practices. Moreover, local sponsors provide with minor financial support within the frames of Corporate Social Responsibility and small contributions are also received from local charities. The intervention follows a rudimentary activity plan, developed by an experienced leader and representative of one of the associations (called The Organiser). From a social policy perspective, however, the means and objectives of the intervention are not articulated and documented in a substantial manner by the partnering actors. In that sense, and in order to grasp the implicit policy articulation, statements describing the intervention are retrieved in interviews. Such articulations provide social policy formulation in practice. Moreover, the intervention has gained both local and national recognition. The program is expanding locally, involving more schools in partnership and also setting up partnerships with associations in other suburban residencies in the municipality. Also, other associations and municipalities have expressed interest in deploying similar ideas as those foundational of Football for Inclusion. This kind of interventions and practices have become increasingly recurring in local and municipal social policy, in Sweden today (Dahlstedt and Ekholm 2018).

\section{Analytical perspective}

In order to understand how Football for Inclusion emerges as part of the welfare state's ambitions to reduce tensions and conflicts in society, to create community and social solidarity between people, we take our theoretical point of departure in a governmentality tradition. This approach makes possible to explore how the formation of local governing practices are aligned with overarching formation of social inclusion, community and solidarity. Here, social inclusion, community and solidarity are approached as discursive formations (Foucault 1972), whose meaning cannot be assumed, but needs to be interrogated and problematized empirically. The theoretical framework is further expounded on in the following facets: first, in a perspective on the relation between problem and solution developed mainly by Foucault (2004) and Bacchi (2009); second, in a perspective on this specific relation highlighting the role of the welfare state as a means of overcoming conflict and forming social solidarity advanced by Donzelot $(1988,1991)$; and third, in a perspective on the relation between 
the state and civil society, and particularly on the conceptualisation of the latter conceived of as a domain and technology of governing permeated by notions of community and social cohesion, developed by Foucault (2008) and advanced by, among others, Dean and Villadsen (Dean and Villadsen 2016; Villadsen 2008, 2016; Villadsen and Dean 2012).

The concept of problematisation is used to illustrate how social problems are formed in discourse, and made ready for governing interventions (Bacchi 2009; Foucault 2004). The ways of understanding reality facilitate action with regard to solutions to the problems in question. Representations of social problems are thus interwoven with solutions in the sense that solutions can be seen as actions against the problems, but also in that the way in which solutions are presented and carried out is crucial to the way in which the problems can be interpreted. Governing is thus a problematising activity by means of portraying of problems in a specific way (Bacchi 2009) and the consequent promotion of various technologies of governing problems portrayed (Miller and Rose 1990). For instance, tensions and conflicts are made visible in the statements analysed and are thus made governable in certain ways. This means that we may analyse the tensions and conflicts that are highlighted, the boundaries and lines of conflict that are created through a specific social policy intervention - in this case football as a means of inclusion.

In line with Donzelot $(1988,1991)$, we approach this particular interweaving of problem and solution as a starting point for examining the rationality of the welfare state, with a particular focus on technologies of solidarity. With the development of modern industrial capitalism in the late $1800 \mathrm{~s}$, and with it an evermore specialised division of labour, Donzelot (1988) argues that a number of social problems appeared leading to an ever increasingly tangible social fragmentation with antagonisms and conflicts between different groups and lack of social solidarity as a result. Accordingly, the ambition of the welfare state was (and is) to combat tensions and conflict and produce social solidarity (Donzelot 1991). Technologies of solidarity aim at protecting the most vulnerable people, which is particularly important as vulnerability create fragmentation and thereby conflicts - in this way social solidarity can be created.

In relation to the welfare state, civil society has been articulated as an arena where community and social cohesion could be formed. Here, we approach civil society as a discursive formation (Villadsen 2008) constructed as a domain where governing takes place. In the liberal tradition, civil society has been understood as a domain beyond the reach of and limiting state government, where the natural rights and freedoms of individuals are guaranteed space (Burchell 1991). In contrast, from a governmentality point of view, civil society is seen to be formed as an integral part of liberal governmental rationality and as a domain where individuals and agencies are addressed as subjects of rights, interests and virtue, as active participants in their own governing (Ashenden 2015; Foucault 2008; Villadsen 2016). This means that distinctions between state and civil society are contingent and constructed specifically in a liberal discourse, as a way of promoting a certain way of governing based on the rights and freedoms of individuals (Dean and Villadsen 2016). This, however, does not mean that civil society is a primary reality exempted from power relations (Foucault 2008). Rather, the emergence and formation of civil society enables more subtle forms of governing than the formal interventions of state government (Foucault 2008). Moreover, Villadsen (2016) argues that the liberal discourse on civil society as limitation of state power is 
underpinned by eschatological notions of social harmony and community. In theological discourse, eschatology refers to the historical end-times when conflicts and disharmony have been over-come. When as the interventions of the state are associated with the exercise of power over individual subjects as well as with a colonising power vis-à-vis civil society, state-phobic notions are nurtured within this liberal discourse (Villadsen and Dean 2012; Villadsen 2016). Accordingly, notions of unity, community and social harmony have underpinned "a discourse on voluntary sector rationality" (Villadsen 2008: 172) influencing social policy in the recent decades. Here, a gradual transmutation of state government in terms of collaboration, network and co-governance between state and civil society (as well as market-based agencies) could be viewed as negotiations aiming to transcend the state and civil society dichotomy and integrate - or even absorb - state power within a civil society rationality (Villadsen 2016), forming a coherent and harmonious social sphere beyond the state (Dean and Villadsen 2016).

By specifically drawing attention to social interventions as technologies of solidarity and as solutions to this particular problematisation, it is possible to examine in more detail the creation of a societal community characterised by harmony and transcendence of conflict and power relations.

\section{Method and material}

The empirical material examined in the article comprises of interviews with representatives and leaders of Football for Inclusion. Altogether, seven interviews were conducted. The Initiator represents the participating associations. He has a substantial network of contacts in the municipality, among politicians and officials. He is also the chairperson and is active in a local charitable foundation. The Organiser is an educated sports teacher, experienced in sports movement management. He is responsible for working out the activity plan. The Sports leader has years of experience of sports management and is also a trained pre-school teacher. He leads the activities with the children within Football for Inclusion. Sports coach 1 describes herself as a "girl and immigrant who plays football and is studying to be a teacher". Sports coach 2 is the youngest of the representatives, assisting the other leaders. The Headmaster from one of the participating schools, is responsible for the contact between the school and the program. The Municipal representative is an official in the municipal administration who is responsible for the projects initiated in collaboration between municipality and civil society, for instance, with respect to the sports activity. The interviews were based on the respondents' own descriptions of sport and particularly football as a means of promoting social inclusion, community and social solidarity. The respondents were selected as they were the most involved in and most well-informed of the practices. At the time of the data collection, the respondents included and accounted for where the key actors performing the intervention.

The interviewers were careful regarding the impact on the respondents' statements with the aim of minimising the interviewers' impact on what was said during the interviews (cf. Cruickshank 2012). The interviews were transcribed verbatim and then analysed as text.

In the analysis, the empirical material was interpreted within the framework of the theoretical perspectives on problem-solution, conflict-solidarity and state-civil society 
presented previously. Consequently, we have interpreted the respondents' statements on Football for Inclusion and on the potential social utility of football with respect to inclusion, community and solidarity. In the process of interpretation, respondents' statements were schematically categorised into the topics of problematisations and solutions. Focusing on how these are interwoven, we were then able to further analyse the basic notions and understandings of conflict and solidarity as well as the role of public welfare and civil society with respect to public-private partnerships.

\section{Research context}

Sport and civil society are today mobilised in webs and networks of welfare providers counteracting the situations and dynamics of social exclusion following increasing segregations and social inequalities, in Sweden and elsewhere (Coalter 2007; Ekholm and Dahlstedt 2017).

In Sweden's disadvantaged suburban areas, dynamics of social exclusion in terms of spatial separation, marginalisation in the labour market and territorial stigmatisation create social, economic as well as educational inequalities, affecting particularly children and youth (Dahlstedt and Ekholm 2018) Today, multi-ethnic suburbs in Sweden are arenas where the tension between conflict and solidarity is played out.

For several decades, the public debate on multi-ethnic suburbs has revolved around the so-called Million Programme (Nord and Nygren 2002; Dahlstedt and Ekholm 2018). This was a large-scale housing programme in the 1960's and 1970's, promoted by the socialdemocratic government, as a means of a general improvement of the standards of housing and living for the broad population. The programme was characteristic of welfarist social policy aiming for redistribution and social equality through state intervention and governing (Tunström 2009). The Million Programme has been described on the basis of its social, and later ethno-cultural, "otherness", with a continuous focus on the conflicts, deviations and problems which the areas create in the form of culture clashes, gang rivalry, drugs, poor school performance and vandalism (Stigendal 2016; Ålund 1997). Today, the disadvantaged suburban areas of the Million Programme are talked about as "areas of exclusion" (Dahlstedt and Ekholm 2018), particularly, due to the areas evoking particular values and cultural expressions characterised by dependency on welfare, alienation, suspicion and political passivity (Davidson 2010). In this context, the young people of the suburb are seen as both the source of conflict and the possible solution to create solidarity: if they are formed or fostered in the right way, there is the opportunity of creating social solidarity - otherwise, the risk is that the destructive spiral of exclusion may deepen (Ekholm and Dahlstedt 2017). Ambitions to counter segregation and to create more inclusive urban landscapes, has in the recent years primarily been based on cooperation between public, private and voluntary actors (Herz 2016; Kings 2011).

Involvement of non-profit actors from civil society have been an increasing feature in Swedish welfare provision (Johansson et al. 2015); not least with respect to short term projects targeting stigmatised suburban areas (Herz 2016). Sweden has a large voluntary sector and civil society relative to other countries (Svedberg and Olsson 2010); however, the influence of civil society in social policy and welfare provision have until recently been of rather minor importance (Johansson et al. 2015). In many ways, new roles for non-profit 
and voluntary organisations are emerging, moving from the role as political agents and advocates of social reform and justice into the role of service providers (Herz 2016; Johansson et al. 2015; Kings 2011), formed in dialogue between state and civil society organisations (Johansson 2011; Norberg 2010). Here, case-based interventions particularly target groups and individuals in suburban "areas of exclusion" (Dahlstedt and Ekholm 2018; Herz 2016). Most notably, local associations have come to play an important role in terms of service provision in marginalised suburbs (Kings 2011).

Recently, the roles of voluntary sport clubs and associations of the civil society as policy providers have been formalised and explicated (Norberg 2011). Stenling and Fahlén (2016: 867) have reviewed Swedish "sport clubs" propensity to act as policy implementers" of social and welfare objectives. Most prominently, one category of clubs - "the social fostering club" - alerts attention to the examinations presented in this article. These clubs' focus is on "the production of democratic, socially integrated citizens", whereby "children and youth can be kept off the streets, out of trouble, and grow in a socially desirable way by engaging in an adult-supervised, meaningful leisure activity" (Stenling and Fahlén 2016: 875). Notably, participation of immigrants and general goals of social inclusion could be viewed in terms of social fostering.

Internationally, sports-based interventions for social objectives has become a way for public authorities such as municipalities to involve civil society actors such as charity foundations and social entrepreneurs in "the social problems industry" (Pitter and Andrews 1997). Research have noted that such practices could contribute to individual resources such as enhanced self-esteem and self-confidence (e.g. FraserThomas et al. 2005; Lawson 2005) and also to community development and social relations (Coalter 2007; Lawson 2005). At the same time, research also indicates that sport can constitute only a limited social policy action as regards taking action against or changing the fundamental conditions which create segregation, tensions, conflicts and problems in society (cf. Coakley 2011; Coalter 2015; Ekholm 2018).

Focusing in particular on sport as a means of promoting social inclusion, there is furthermore a risk of social inclusion being seen as equivalent to adaptation and assimilation to specific norms and pre-defined ideals of the majority (Ekholm and Dahlstedt 2017; Forde et al. 2015; Hylton 2011; Long et al. 2014). From a social policy perspective, it can be highly problematic if interventions promoting social inclusion in practice involve strategies for assimilation where the social inclusion and participation of one group is based on the adaption to the other group, on the other group's terms (Ekholm and Dahlstedt 2017). Even though based on a problematic distinction (cf. Blackshaw and Long 2005), another aspect of promoting social inclusion noticed in research stresses differentiation between exclusive bonding and inclusive bridging: social inclusion can involve both strengthening of bonds within delimited groups, and thereby stronger delimitation against other groups (exclusive bonding), but also the creation of more inclusion and bridging contacts between different groups (inclusive bridging) (Coakley 2011).

\section{Analysis}

The following analysis starts with an account of how one of the main problems created due to these tensions and conflicts are described by representatives of Football for Inclusion, that of self-generating social exclusion and exclusive bonding. In this 
specific problematization, the Area is portrayed as a problematic, parallel society, actively contributing to its own exclusion. The solutions promoted as a response to these problems are then outlined, with particular focus on football as a technology of solidarity. The analysis shows how Football for Inclusion is organised in order to deal with the challenges of self-generating social exclusion and exclusive bonding, and that is in collaboration between various actors, in the form of an associationlike arena where people can meet and where a set of norms and ideals of social inclusion and solidarity can be fostered among the participating children, not least by means of role-models modelling the desired conduct and acting as conductors of social inclusion.

\subsection{The problem of self-generating social exclusion and exclusive bonding}

One argument recurring in the interviews is that the parents' lack of resources and skills also constitutes a problem for Swedish civil society, and for sport associations in particular - especially when it comes to their opportunities to meet the children in the Area and to get them to participate. The Organiser thinks that, in turn, this problem has resulted in several of the associations which have been active in the Area have been forced to close down parts of their previous activities:

It is quite difficult to work in an area where there are many immigrants, partly because there is fairly poor patronage among parents and it is difficult to get leaders to join in [excerpt 1].

According to this argument, the parents do not get involved in civil society, at least not by involving themselves as leaders. In turn, it is said that this lack of involvement makes it difficult to establish the kind of civil society activities described by those interviewed as an important means of creating social inclusion as well as cohesion and solidarity.

I think that the biggest racists are actually the immigrants themselves a lot of the time. Against... well... different peoples [folkslag]. Imagine that it is Swed... Swedes are against the immigrants, but... I can say that it... they are much tougher against one another than we are in that direction. Yes, in common parlance and short temper and heat of the moment... "whore"... here and there [excerpt 2].

Here, the category of "immigrants" is described as consisting of different groups or, as the saying goes, "peoples". Although these groups differ from one another, altogether, the "immigrants" differentiate themselves from the "Swedes", particularly in the respect that they are tougher and have hotter temperaments than "Swedes" do. Such a characterisation echoes popular stereotypes of "immigrants" and "Swedes" identified in previous research (cf. Fundberg 1996). In the interviews, the differentiation between "immigrants" and "Swedes" is expressed particularly in relation to civil society and the way in which different groups participate in organisations of civil society. One recurrent line of argument is that "immigrants", mainly by organising themselves into their "own" associations and socialising with those who are more "like" their own "people", 
are differentiating themselves from "Swedes" and the "Swedish", assumedly undermining community and solidarity. According to this line of argument, "immigrants" are described as establishing associations which strengthen the bonds within the own ethno-cultural community, while excluding them from the rest of society. According to the Municipality representative, the majority of those from the Area who come to the municipality to start an association targeting their own "fellow countrymen", which the municipality does not view in a completely positive way:

Among those who approach us and want to form an association, and they might want to do so with their fellow countrymen... it feels like a certain security to do so. If you want to put together your football team and you want it to be your people [folkslag] only, we try to get people to cooperate. Sometimes it is possible, but often they want their own because there is a certain amount of security in that [excerpt 3].

In contrast to excerpt 1 , where the parents were described as lacking in terms of involvement when it comes to supporting their children's participation in civil society and football, there is here a specific form of involvement and participation emerging aimed at one's 'own' group. Such involvement is certainly understandable - "there is a certain amount of security in that" - but it is still portrayed as somehow problematic, with respect to social inclusion and solidarity. A desirable involvement, and technology of solidarity, is conceptualised as based on "cooperation", another recurrent topic that we will focus on in the following, in relation to possible and desirable interventions. In both excerpts 1 and 3, then, involvement is described in terms of problems: involvement is understood as constituting a problem in the Area in the form of lack of as well as the occurrence thereof.

In excerpt 3, the different groups living in the Area is once again referred to in terms of specific "people". In the quote, there is a particular form of solidarity emerging, which differs from the inclusive kind of solidarity that is seen as desirable - including different groups, transcending the borders between inside and outside. The form of solidarity taking shape among the groups living in the Area, however, is based on the principle of sameness and community - a sense of belonging "with your compatriots" within the exclusive "people". Here, the exclusive bonds are strengthened primarily within the group. Such inward-looking community-formation is described as further deepening the dynamics of exclusion which threatens social solidarity, not just in the City but also in society as a whole. The Initiator is one of those highlighting the dangers of such inward-looking community-formation in the Area.

The young people in that association have a very narrow background. They come from an area in South America [and are part of the Chilean association]. They generally speak Spanish during their training sessions and so on. Or if you take Syrians or... Balkans. This is a big problem in [the City] but also throughout Sweden [excerpt 4].

According to this description, it appears as though the processes generating and deepening the state of exclusion, undermining cohesion and solidarity, in the Area and the City as a whole are driven by a kind of seemingly natural, inherent logic. One 
main problem here is that those living in the Area enclose themselves in "their" own associations. As a consequence, they are step by step from disconnected from the surrounding society. In excerpt 4, the language emerges as an important symbol for the rationality of exclusion. With the young people in the Area organising themselves into separate associations where they can - or actually should - speak languages other than Swedish, the boundaries between the inside and the outside are recreated and even strengthened.

\subsection{The solution of public-private collaboration, mobilisation and transcendence}

As described earlier, Football for Inclusion, like many other contemporary social policy interventions, is based on collaboration - partnership - between public and private, state and civil society actors, seen as a strategy of governing social inclusion and solidarity. Collaboration gives various actors the opportunity - in this case the school in collaboration with civil society and private actors - to meet, identify and initiate joint projects which bring together diverse resources, skills and desires. With this collaboration, there is an arena established, for talking, sharing experiences and coordinating information and resources. The different actors involved in collaboration all highlight the value of collaboration for the individual actors and for the activity as a whole. For example, the Headmaster describes the practices as having a great potential for the school.

I imagine that what we've initiated together with the people behind the project is positive. We've succeeded in creating this organisation with a mix of theory and practice working with values and suchlike, which is very good. Here in school, football is played at every break and Football for Inclusion can be involved in developing these children on a more organised level - how to behave on a football pitch, for example. And, in the long term, I think it is guaranteed to reduce a lot of conflicts arising [excerpt 5].

From the Headmaster's point of view, collaboration under the auspices of the activity creates added value for the school, particularly by opening up an arena for fostering where the children can develop the social and cultural skills and acquire the norms and values create solidarity between individuals. The Headmaster hopes that the interventions made under the auspices of Football for Inclusion, "working with values and suchlike" can "develop these children on a more organised level", which is "guaranteed to reduce a lot of conflicts" in the long term, in school and in society at large. We will return to the question of fostering and the specific social and cultural skills, norms and values the children are expected to acquire by participating in Football for Inclusion further on.

Let us first focus on the Headmaster's approach to collaboration and its potential. Here, the sector division between state and civil society are noted. This division needs to be maintained, negotiated and transcended. In the Headmaster's description, collaboration is, on the one hand, based on the crossing of boundaries between different areas of interest and activities and the searching for common solutions, most explicitly emphasised by Initiator. On the other hand, in his description, he also highlights that there is a certain preservation of boundaries between different areas of interest and 
activities. Although the Headmaster himself sees a great value and potential in the fostering elements in the activity, he is quite sceptic about the plans about developing methods to provide with homework in collaboration between the activity and the school.

When I spoke to [the Initiator], he was interested in developing some kind of collaboration concerning help with homework and suchlike. I somehow think that the school should be responsible for the pedagogic matters, and it might sound as though I do not want anyone going into my domains, as it were, but I do not want to build a society where we [the school] make ourselves dependent on others, for a task that the school should deal with. It's our responsibility to see to pupils' knowledge and knowledge progression [excerpt 6].

The quote illustrates the negotiations regarding responsibilities and boundaries between different areas of interest and ways of understanding welfare arising when between different actors are engaged in collaboration, including the school and associations in civil society. In the Headmaster's description of collaboration, there is an explicit tension. On the one hand, there is an ambition within the activity to provide with voluntary support to children who find it difficult to keep up at school and who lack the right support from home for this. In that respect, Football for Inclusion emerges as a philanthropic initiative aimed specifically at the excluded. On the other hand, the Headmaster is careful to maintain a welfarist ambition of strengthening social solidarity, where the school has the overall responsibility for children's learning, which does not allow the children to be dependent on either their parents' level of education, support or charitable initiatives from civil society. Following such a line of argument, the Headmaster strongly highlights the pupils' learning as a responsibility for the public, not for the voluntary sector.

\subsection{The solution of building the association-like organisation}

Football for Inclusion is, as shown above, based on collaboration. It takes the form of a meeting place for different actors, but it also takes the form of a place where people and different groups in society can meet. In this sense, it is constructed as a site of collaboration, cooperation and solidarity between people, that is children, youth, parents, coaches and organisers, as well as welfare providing agencies, that is sport associations, schools, municipal government and administration. This meeting place is not an association and is not strictly organised like a football association. It rather is animated as an association-like place, a place where children, youth and parents can be introduced to civil society. Assumedly, the construction of the association-like form of organisation is promoted to resemble a notion of authentic forms of associational life, in civil society, where all people and all children can be included in community and participate in sport. In this sense the form of organisation is a construct and artefact, a discursive formation, making possible a certain form of community and social inclusion.

In the following way, the Male sports coach with insight describes his feelings of exhilaration of how some of the participating children see Football for Inclusion as "their football team". 
There are many who do not play in a football club... there was someone who said: "Oh, I play for Football for Inclusion!" Oh, that's great to hear. They see this as their football team [excerpt 7].

Participating in football and being introduced to civil society at this association-like place means that the children can be fostered in a way that aligns with the intervention rationale of social inclusion. In the interviews, participation in civil society and in the particular form of sports associations is described as a crucial part of the participation in Swedish society as a whole. It is thereby seen as particularly important that children from families who are less used to participate in such associations to be introduced to sport and civil society more broadly. The hope - the Sports leader emphasises - is to create among the children a desire and an interest in playing, continuing to play - and to gradually work their way up to a "real" association.

It is hoped that these children think it is fun to come here, that they learn something, obviously, when it comes to football. They might fancy continuing to play and have made a few new friends from other schools, when we then later on have several schools together. That's what I'm hoping for. And then obviously, in the end, we want them to want! That we can create an interest in continuing to play football in an association when they leave Football for Inclusion, become too old or might fancy starting in an association and that we can help them get in, depending on where they live. We might be able to talk to a nearby club and tell them they can ring here and, hey, we can help them get in there if that's what they want... so that they continue to have an interest and guide them into activity and life in associations, which I think is good. I do like civil society associations... I myself have gained so much from civil society activity all my life... [excerpt 8].

Here, Football for Inclusion is animated as a bridge between the outside, the excluded life in the Area, and the inside, social inclusion and participation in the Swedish civil society. The aim of the children's participation in the practices is not simply for the children to develop their sporting skills. Rather, the aim is for the children to be in an environment where they can meet children from other parts of the city and - in particular - committed adults who can "guide" the children to social inclusion. This association-like organisation is conceptualised as an arena for cultural meetings, where the boundary between inside and outside can be crossed and where integration, and a kind of solidarity, can be achieved. In these terms, the Sports leader describes the playing of football as a way of "getting to know one another".

I really believe in civil society and sport as a means to integrate with each other, to get to know one another and learn to understand and respect one another. That's where we meet and if we meet many times, although we're from different cultures, I also believe people will respect one another and start to understand one another [excerpt 9].

On the basis of how the Sports leader (excerpts 1 and 9) talks about how people with different background can have difficulties understanding one another, the activity as 
well as civil society at large and associations appear as a meeting place where people can get to know one another and themselves. The Sports leader clarifies his reasoning by drawing the following historical parallel:

People used to say that there should be an association in every village, that there should be an association close to everyone to act as a gathering point where people can come to play sport, whatever sports it may be. [...] People say that the biggest and best recreation centre is the sports complex. People meet there. There are rules to follow. You have to learn the rules [excerpt 10].

The sports complex is described here as a "gathering point", where everyone can meet and where community can be formed and governed. The recreation centre metaphor is telling. This place is seen as a pedagogic arena where "there are rules to follow". Accordingly, the participants will be fostered in specific ways, according to specific norms. Here, the boundaries and tensions in society can be overcome by fostering. In a similar way, the Headmaster describes civil society as an arena of opportunities and learning, with a range of positive effects way beyond the realms of civil society.

I think integration work spans more than the six hours you are at school. You must look at the total amount of time children and people have. There, voluntary organisations, civil society activities (whether they be football, scouts or whatever you can think of) are a way into a larger interface for people. It creates nothing but positive effects. That you become someone in a context. [...] not just that you get to keep yourself busy [...] but you also gain contacts [excerpt 11].

\subsection{The solution of conducting social inclusion by means of modelling}

How, then, is the activity initiated as such an arena of opportunities? When it comes to creating this arena and the learning processes leading the children to social inclusion in society having the right leaders with the right leadership is described as crucial. With regard to leadership, there is a specific type of leadership emerging in the stories. According to the Initiator, the explicit aim of Football for Inclusion is to develop activities based on "modern pedagogy", with a coaching staff consisting of educated "recreational workers and people who have worked with football activities as well as having training within the field". At the same time, other recurring abilities among the leaders are emphasised with regard to how the children can be shaped in a desirable direction. Here, it is primarily the leader's capacity as "role model" which are highlighted. For example, the Female sports coach describes her role as leader as follows (for a further developed analysis of the gendered dimensions of rolemodelling practices, see Ekholm et al. 2018).

My role is to teach football, to be a role model. [...] I believe that my main role is... well, they, the girls, look up to me a bit. I'm a girl and play football, and... they think I'm clever and all that so they just want someone to look up to so they also know they can manage it. Increase their self-confidence, show that a girl can 
play football. It's not only for boys. And allow them a bit of space. Be there and push them. [...] Many immigrants have prejudices against girls playing sport in general. And helping them, well, if they wanted me to I'd be very happy to help them. If I need to speak to their parents, I can do that. In principle I could do anything to help them, if they wanted to play football or something else [excerpt 12].

For the Female coach, leadership is about being a good "role model" in her conduct in front of and together with the children, someone who the children can identify with and whose good example they can imitate in their own behaviour and in their own life. Here, the specific personality and experience of each "role model" constitute a great trust-forming capital, which obviously can be different and used differently, as a means of governing the conduct of children and youth, by each and everyone (cf. Ekholm 2017). In her particular case, being a "role model" means being a "girl" and an "immigrant". She sees her role as "role model" as particularly important with regard to the prejudices among "immigrants" about how it is to be a girl in sport, which in itself can contribute to or even deepen existing exclusion. She describes her leadership in terms of pushing, helping and giving self-confidence primarily to "them", i.e. girls with "immigrant" background - as she (cf. Ekholm et al. 2018). In this context, her own experiences can be very useful: "My parents moved here and they have integrated, so I know how it happens, and it's not as easy as everyone thinks and all that". In relation to her position as "role model", with emphasis on her specific personal experiences, the fact that, while she is involved in Football for Inclusion, she is also studying at the university to be a teacher is not mentioned. This experience and possible competence is not portrayed as equally prominent and valuable in her leadership. It is based on the traits as a role-model she, and other of the leaders and coaches, are being constructed as conductors of social work and social inclusion - guiding the children from exclusion to inclusion (cf. Ekholm 2017).

The Sports leader, with many years of experience as a pre-school teacher, also describes his leadership primarily in terms of being a "role model", where it is a matter of giving a good example in different ways.

I try to be a role model, to see everyone. [...] That is where I believe civil society... we can't do everything, but I think it plays a really big role in fostering our children and young people. Being a decent fellow human being, irrespective of where we come from. This is where I think sport - irrespective of which one has quite a lot of power, positive power, to be able to influence [excerpt 13].

When describing in more detail the effect of being a "role model", he also talks on the basis of his own biography and a specific person who was a "role model" for him when he was young:

I may not always have listened to what my mother said, nor to my teacher, but I listened to what my trainer said when I played as a youngster. [...] We have a big influence and then it's important for us to be a positive role model. And I think we'd be influencing in the other direction if we weren't. [...] I do of course think it's really great to foster an Elite football player, but it's also great to have had girls and boys who, when they're 30-35, appear in town and say "Damn, what 
fun we had when we were at Football for Inclusion". The fact that you will meet them even in a dark alley late at night without being in any danger, that's what I see as my goal as leader [excerpt 14].

In spite of different backgrounds, experiences and personalities, when meeting the children, the leader personifies and, in a way, defines what is normal and desirable, according to which the children are expected to be fostered by participating in football (cf. Ekholm and Dahlstedt 2017). This means to be "a decent fellow human being" (excerpt 13), to contribute to a local community where everyone feels safe and where people can meet "in a dark alley late at night without being in any danger" (excerpt 14), and in that sense embodying community and solidarity. Such community and forms of social inclusion are perceived as possible when following in the paths and guidance of the formative role-models.

\section{Discussion}

In the analysis, the interweaving of problem and solution have been analysed, focusing specifically on the form of organisation established to counter the problems and to host the technologies of governing and providing social inclusion. Here, social exclusion has been problematized by the respondent representatives in terms of ethno-cultural boundaries enforced by residents themselves creating self-generated exclusion, which in turn, creates an encapsulated environment for social problems and exclusion to grow. This means that the analysis focus on how knowledge about problems and solutions are constructed and how they underpin and are intertwined with organisation of certain governing technologies. Thus, we have no empirical material nor theoretical concepts or approaches to assess the potential success or failure of the intervention and its objectives, or of assessing how the targeted children and youth respond to or become integrated in the activities and practices performed - this is not part of our ambition. Rather, we have examined the rationalities and technologies of inclusion, community and solidarity underpinning the practices and organisation as well as their potential discursive effects.

Conceived of as a solution and as a measure of governing technology, the sportbased intervention provides an association-like arena for "role-models" to enact proper conduct and Swedish-ness and to be conductors of social inclusion. Importantly, the form of organisation and arena is enabled by collaboration between a range of municipal and civil society actors. In this way, non-profit and voluntary organisations of the civil society are integrated as providers of social service (cf. Hertz 2016) and implementors of social policy (cf. Stenling and Fahlén 2016), in particular located in the suburban periphery and targeting what is perceived as local challenges of exclusion (cf. Dahlstedt and Ekholm 2018).

Here, the association-like organisation constitutes a discursive formation where boundaries between municipal welfare provision and civil society could be seen to be negotiated and transcended. In particular, the negotiations seem to construe a meeting place, facilitating meetings between children from different backgrounds, between children and role-models as well as between public and civic forms of welfare provision and social inclusion rationales. 
In a way, the rationale of the association-like organisation is to overcome the boundaries between children to form a community, and to use the community between children and "role models" to promote social inclusion and to rearrange the distinctions between municipal public welfare and civil society associations. This involves the creation of unity and community in a variety of ways.

Perhaps the most notable feature of the analysis is how it centres around the notion of the leaders as "role-models" and thereby conductors of social inclusion. "Role-models" are shaped as representatives of Swedish-ness, potentially guiding the excluded youths across the boundaries between exclusion and inclusion. Based on their particular background and experiences from Swedish civil society and sport associations, they represent not only the included society and Swedish-ness, but also a somewhat nostalgic notion of the historical role of civil society and sport associations in Sweden - "there should be an association in every village [with] rules to follow" (excerpt 11). By looking back on the historic role of associations in Sweden and by conceiving of sport practices as a means of creating community and solidarity, it is assumed that the problems of segregations and conflicts of today could be countered. Here, such practices become arenas for integrating and understanding each other as well as regulating conduct and fostering certain values and norms, diligence and pro-social development. As the leaders and coaches are represented as authentic in their relations to the youths, they are seen as having inherent qualities making it possible for them to reach out to the children and to influence them. This could only be played out in an arena characterised by genuine and authentic interaction with the human touch of civil society.

Still, Football for Inclusion is not an ordinary association of the sport federation, not a "social fostering club" (cf. Stenling and Fahlén 2016) or of civil society in general, it is rather a practice where welfarist social objectives are the very premise of the activities; it is a means of, or an instrument constituted in relation to, certain social policy objectives integral in the welfare state, stifling conflicts and producing community and social solidarity. This alerts attention to the relation between the welfare state in the shape of the municipality, the administration and public schools and the civil society, negotiated and forming the association-like arena. By analysing these specific negotiations as they are taking place in Football for Inclusion, some reflections on the relation between the state and civil society could be made. Reassessing the theoretical framework presented, this negotiation and transcendence could be interpreted in a few different ways.

First, the formation could be viewed as a way for welfarist rationality and the municipality to intervene in and to instrumentalize the autonomous civil society. In the analysis, such interpretation is underpinned by the ways in which the representatives conceive of themselves as instruments of social policy objectives. That is not by answering to formal expectations of the municipality or from the public administration, but rather by promoting themselves as actors in welfare provision - a kind of selfinstrumentalization, perhaps, in order to sustain their position as a vital player in the community and to promote themselves as an eligible partner in the provision of welfare. In this sense, the association-like organisation becomes a way for welfarist rationales of governing to reach-out-into the problem areas of the suburban periphery. However, it would be easy, and also simplified, only to see the establishment of an association-like arena as a way for the welfare state to instrumentalize elements of the sport movement and civil society. 
Second, the formation of the association-like organisation may be interpreted as a way for the forces of civil society to intervene in and to informalize practices traditionally maintained by public and municipal agencies by means of providing for social inclusion and cohesion. This relation, perhaps most clearly, is negotiated in the excerpt where the Headmaster expresses his hesitation and reluctance before Football for Inclusion and the ambition to provide for help with homework and other pedagogic matters. Initiatives in this direction, generally, are taken by means of adopting the social policy ambition to counter tensions and conflict and promote community and social solidarity. In line, this is made possible by relocating the line of conflict from a socioeconomic notion of segregation to an ethno-cultural representation of otherness and self-generated exclusion. This relocation make solutions based on the fostering of conduct, values and norms possible, guided by semi-professional "role-models" - in contrast to economic redistribution, as a response socio-economic inequalities. It is the leaders, on basis of their role-modelling competences and using their experiences from civil society association, that youths could potentially be guided, by means of norms and values, from exclusion to inclusion (cf. Ekholm and Dahlstedt 2017).

Even though both of these interpretations may well grasp important aspects of contemporary forms of public-private collaborations, they seem limited, at least in one certain respect, empirically visible here. Notably, objectives such as community and social solidarity, are by no means goals exclusively located to either side of this traditional sector divide separating municipality and statist welfare from communitarian ideals of civil society. Both interpretations are based on upholding the distinction between separate sectors in welfare provision and on processes of negotiation between them. These distinctions are, rather, contingent and arbitrary, constituted in discourse and established in practice first when acted upon. We cannot see the practices as either a way for the state to colonise civil society or as a way for civil society to penetrate the formal bureaucracy and rigidity of the welfare state. Instead, Football for Inclusion forces us to question the notion of the classic sector divide - here, between state (in the form of municipal agencies and public schools) and civil society (in the form of local sport clubs). Here, the form of intervention and organisation could not be located to or limited within the scope of either the welfare state or the civil society. Nor is it a hybrid of them both. Rather, Football for Inclusion highlights that the very distinction between traditional welfare providing sectors are arbitrary, and that the welfare state and civil society are embedded within each other. It particularly highlights that we need to look beyond this divide in order to focus on how social problems are countered in contemporary society. Thus, we argue that the association-like organisation may rather be understood by focusing on the assemblages of technologies promoted in order to shape community and solidarity, than by focusing on the sector belonging of the partners involved and the negotiations between them.

In that way, the form of organisation and technologies of governing imbued aims to counter tensions and conflict by means of abolishing power relations, not only between geographical areas of the segregated city and the resident individuals and children, but moreover, and more importantly, by means of eradicating the distinctions between collaborating actors and welfare providing sectors. Here, nostalgic notions of Swedishness and of the associational life of the sport movement and the civil society community is articulated as a container of harmonious, cohesive and conflict-free patterns of interaction. Furthermore, this implies an anti-political eschatology and vision where 
conflict and notions of power relations are supressed (cf. Villadsen 2016). Consequently, the importance and relevance of social and economic dimensions of power relations in terms of segregation and social exclusion are downplayed and (hence) not addressed in the social policy articulated and performed.

Funding This study was supported by the Swedish Research Council for Sport Science under Grant number P2017-0159.

\section{Compliance with ethical standards}

Disclosure of potential conflicts of interest We declare no conflict of interest.

Open Access This article is distributed under the terms of the Creative Commons Attribution 4.0 International License (http://creativecommons.org/licenses/by/4.0/), which permits unrestricted use, distribution, and reproduction in any medium, provided you give appropriate credit to the original author(s) and the source, provide a link to the Creative Commons license, and indicate if changes were made.

\section{References}

Ålund, A. (1997). Multikultiungdom. Lund: Studentlitteratur.

Ashenden, S. (2015). Foucault, Ferguson and civil society. Foucault Studies, 20, 36-51.

Bacchi, C. (2009). Analysing Policy. French Forest: Pearson.

Blackshaw, T., \& Long, J. (2005). What's the big idea? Leisure Studies, 24(3), 239-258.

Burchell, G. (1991). Peculiar interests: Civil society and governing 'the system of natural liberty. In G. Burchell, C. Gordon, \& P. Miller (Eds.), The Foucault effect (pp. 119-150). Chicago: University of Chicago Press.

Coakley, J. (2011). Youth sports: What counts as "positive development". Journal of Sport \& Social Issues, 35(3), 306-324.

Coalter, F. (2007). A wider social role for sport: Who's keeping the score? London: Routledge.

Coalter, F. (2015). Sport-for-change: Some thoughts from a sceptic. Social Inclusion, 3(3), 19-23.

Collins, M., \& Haudenhuyse, R. P. (2015). Social exclusion and austerity policies in England: The role of sports in a new area of social polarisation and inequality? Social Inclusion, 3(3), 5-18.

Cruickshank, J. (2012). The role of qualitative interviews in discourse theory. Critical Approaches to Discourse Analysis across Disciplines, 6(1), 38-52.

Dahlstedt, M., \& Ekholm, D. (2018). Social exclusion and multiethnic suburbs in Sweden. In B. Hanlon \&T.J. Vicino (Eds.), The Routledge companion to the suburbs (pp. 163-172). New York: Routledge.

Davidson, T. (2010). Utanförskapelsen. Socialvetenskaplig Tidskrift, 17, 149-169.

Dean, M., \& Villadsen, K. (2016). State phobia and civil society. Stanford: Stanford University Press.

Donzelot, J. (1988). The promotion of the social. Economy and Society, 17(3), 395-427.

Donzelot, J. (1991). The mobilization of society. In G. Burchell, C. Gordon, \& P. Miller (Eds.), The Foucault effect (pp. 169-180). Chicago: University of Chicago Press.

Ekholm, D. (2016). Sport as a means of responding to social problems. Rationales of governing welfare and social change, [Doctoral dissertation]. Linköping: Linköping University.

Ekholm, D. (2017). Mobilising the sport-based community. Nordic Social Work Research, 7(2), 155-167.

Ekholm, D. (2018). Governing by means of sport for social change and social inclusion. Sport in society. https://doi.org/10.1080/17430437.2017.1417986

Ekholm, D., \& Dahlstedt, M. (2017). Football for inclusion. Social Inclusion, 5(2), 232-240.

Ekholm, D., Dahlstedt, M., \& Rönnbäck, J. (2018). Problematizing the absent girl. Sport in society. https://doi. org/10.1080/17430437.2018.1505870.

Fahlén, J., \& Stenling, C. (2015). Sport policy in Sweden. International Journal of Sport Policy and Politics, $8(3), 515-531$. 
Forde, S. D., Lee, D. S., Mills, C., \& Frisby, W. (2015). Moving towards social inclusion. Sport Management Review, 18, 126-138.

Foucault, M. (1972). The archaeology of knowledge. London: Tavistock.

Foucault, M. (2004). Polemics, politics, and problematizations. In P. Rabinow (Ed.), The Foucault reader (pp. 381-390). London: Penguin Books.

Foucault, M. (2008). The birth of biopolitics: Lectures at the Collège de France, 1978-79. New York: Picador.

Fraser-Thomas, J., Côté, J., \& Deakin, J. (2005). Youth sport programs: An avenue to foster positive youth development. Physical Education and Sport Pedagogy, 10(1), 19-40.

Fundberg, J. (1996). Möten på fotbollsplan. Stockholm: Mångkulturellt centrum.

Government Offices. (2015). Ökat anslag till idrottsrörelsen i kommande vårproposition. Press release, 201504-14.

Herz, M. (2016). "Then we offer them a project" - The production of projects in social work conducted by civil society in Sweden. Journal of Civil Society, 12(4), 365-379.

Hylton, K. (2011). Sport and social integration. In B. Houlihan \& M. Green (Eds.), Routledge handbook of sports development (pp. 100-113). London: Routledge.

Johansson, M. (2011). I dialogens namn, [Doctoral dissertation]. Växjö: Linnaeus University.

Johansson, H., Arvidsson, M., \& Johansson, S. (2015). Welfare mix as a contested terrain: Political positions on government-non- profit relations at national and local levels in a social democratic welfare state. Voluntas, 26, 1601-1619.

Kings, L. (2011). Till det lokalas försvar. Lund: Arkiv.

Lawson, H. A. (2005). Empowering people, facilitating community development, and contributing to sustainable development. Sport, Education and Society, 10(1), 135-160.

Long, J., Hylton, K., \& Spracklen, K. (2014). Whiteness, blackness and settlement. Journal of Ethnic and Migration Studies, 40(11), 1779-1797.

Miller, P., \& Rose, N. (1990). Governing economic life. Economy and Society, 19(1), 1-31.

Norberg, J. R. (2010). The development of the Swedish sport movement between state, market and civil society. In A. Evers \& A. Zimmer (Eds.), Third Sector Organizations Facing Turbulent Environments (pp. 183-201). Baden Baden: Nomos.

Norberg, J. R. (2011). A contract reconsidered? Changes in the Swedish state's relation to the sports movement. International Journal of Sport Policy and Politics, 3, 311-325.

Nord, L., \& Nygren, G. (2002). Medieskugga. Stockholm: Atlas.

Pitter, R., \& Andrews, D. L. (1997). Serving America's underserved youth. Quest, 49(1), 85-99.

Schierup, C.-U., Ålund, A., \& Kings, L. (2014). Reading the Stockholm riots. Race and Class, 55(3), 1-21.

Stenling, C., \& Fahlén, J. (2016). Same same, but different? International Review for the Sociology of Sport, $5(7), 867-883$.

Stigendal, M. (2016). Samhällsgränser. Stockholm: Liber.

Svedberg, L., \& Olsson, L. E. (2010). Civil society and welfare provision in Sweden: Is there such a thing? In A. Evers \& A. Zimmer (Eds.), Third Sector Organizations Facing Turbulent Environments (pp. 225251). Baden Baden: Nomos.

Tunström, M. (2009). På spaning efter den goda staden. Om konstruktioner av ideal och problem $i$ svensk stadsbyggnadsdiskussion, [Doctoral dissertation]. Örebro: Örebro University.

Villadsen, K. (2008). Doing without state and civil society as universals: 'Dispositifs' of care beyond the classic sector divide. Journal of Civil Society, 4(3), 171-191.

Villadsen, K. (2016). Michel Foucault and the forces of civil society. Theory, Culture and Society, 33(3), 3-26.

Villadsen, K., \& Dean, M. (2012). State-phobia, civil society, and a certain vitalism. Constellations, 19(3), 401-420. 